\title{
OS RISCOS ASSOCIADOS À PRÁTICA DA AUTOMEDICAÇÃO NO TRATAMENTO DA COVID-19
}

\author{
THE RISKS ASSOCIATED WITH THE PRACTICE OF SELF-MEDICATION IN \\ THE TREATMENT OF COVID-19
}

Kaila Beatriz De Jesus Teixeira, Luana Padovani, Vitoria Regina Melek*, Yohanna Milena Vujanski, Jacqueline Godinho.

UNINGÁ - Centro Universitário Ingá, Maringá, PR, Brasil. *vrmelek@gmail.com

\section{RESUMO}

A COVID-19 é uma doença infecciosa causada pelo coronavírus da síndrome respiratória aguda grave, a SARS-CoV-2. Esta é transmitida por meio de secreções, disseminadas por pessoas infectadas. As principais manifestações clínicas são: febre, tosse seca, cansaço, fadiga, falta de ar, dor de cabeça, náusea ou vômito. Infelizmente, não há até o momento, protocolo farmacoterapêutico para a covid-19, consequentemente, há grande disseminação de informações sobre alternativas terapêuticas sem estudos clínicos ou ainda estudos preliminares. Dessa forma, houve crescentes taxas de automedicação com fármacos como a azitromicina (AZT), ivermectina (IVT), hidroxicloroquina $(\mathrm{HCQ})$, cloroquina $(\mathrm{CQ})$ entre outros, os quais até o momento não possuem eficácia comprovada frente a doença podendo, até mesmo, gerar efeitos tóxicos. Neste contexto, o objetivo do presente estudo foi avaliar os principais medicamentos utilizados na automedicação da Covid-19, bem como as principais reações adversas que podem ser apresentadas pelos pacientes. Para tanto, realizou-se uma busca sobre os principais fármacos utilizados na farmacoterapia da Covid-19 através do DATASUS. A partir disso, constatou-se que os fármacos mais utilizados foram a HCQ, CQ, AZT e IVT, algumas destas utilizadas em associação. Com base nestes resultados foram avaliadas as possíveis reações adversas e riscos relacionados ao uso destes fármacos. A HCQ na dosagem de $600 \mathrm{mg}$ em associação a CQ resultou em aumento da temperatura corporal e prolongamento do intervalo QT, este último parâmetro também foi evidenciado na associação da $\mathrm{HCQ}$ com a AZT. Em relação a IVT houve manifestação de distúrbios gastrointestinais, fraqueza muscular, taquicardia, hipotensão, ataxia, rabdomiólise e coma. Contudo, há pouca informação na literatura sobre os possíveis efeitos adversos destes fármacos como automedicação para a doença por se tratar de algo recente. A automedicação acarreta graves riscos à saúde da população, que motivada pelo medo de uma nova doença, busca alternativas farmacológicas sem comprovação científica ou, ainda, que apresentam resultados preliminares, os quais não asseguram seu uso. Vale ressaltar que devido a urgência do estabelecimento de um protocolo terapêutico para a Covid-19, muitos estudos têm sido publicados com resultados divergentes e pequena amostragem o que dificulta a real percepção dos possíveis efeitos terapêuticos e adversos relacionados à farmacoterapia da Covid-19. Diante do exposto, destaca-se a 
necessidade de demais pesquisas que avaliem os riscos do uso indiscriminado das estratégias terapêuticas utilizadas para o tratamento da Covid-19.

Palavras-chave: Automedicação. Betacoronavirus. Covid-19. Efeitos colaterais. Farmacoterapia. Reações adversas relacionados a medicamentos. 